ISSN: 2162-3104 Print/ ISSN: 2166-3750 Online

Volume 8, Issue 4 (2018), pp. 1497-1521

(C) Journal of International Students

http://jistudents.org/

doi: $10.5281 /$ zenodo. 1467805

\title{
An Academic and Cultural Transition Course for International Students: Efficacy and Socio- Emotional Outcomes
}

\author{
Nelson C. Brunsting \\ Wake Forest University, USA \\ Andrew C. Smith \\ Wake Forest University, USA \\ Corinne Zachry \\ Wake Forest University, USA
}

\begin{abstract}
The current study details changes in first-year international undergraduate students' perceived knowledge of, confidence in, and usefulness of intercultural skills in specific US university contexts after completing a semester-long academic and cultural transition course at a mid-sized private university. Results revealed significant increases in participants' ( $n$ = 42) perceived intercultural competence, perspective shifting, suspending judgment, self-advocacy, and interacting in class with students of other cultures; participants also reported significantly higher campus belonging and social support than a comparison group of students at the university who were not enrolled in the course $(n=32)$. These findings provide initial evidence for the potential of transition courses to increase intercultural skills and campus belonging for first-year undergraduate international students attending US universities.
\end{abstract}

Keywords: belonging, intercultural competence, international student, social support, undergraduate 
The transition to US colleges and universities can be an exciting and challenging experience for first-year undergraduate international students. Unfortunately, not all foreign students entering US colleges and universities experience a positive transition into their institutions (Andrade, 2006a; Smith \& Khawaja, 2011), and problematic transitions lead to negative outcomes for international students, including stress, depression, and lower academic achievement (Poyrazli \& Kavanaugh, 2006; Wang et al., 2012; Wei et al., 2007). Researchers have identified both internal factors (e.g., sense of campus belonging) and external factors (e.g., social support) that can positively influence international student adjustment outcomes (see Poyrazli, Arbona, Nora, McPherson, \& Pisecco, 2002; Smith \& Khawaja, 2011; Sullivan \& Kashubeck-West, 2015). While it is necessary for researchers to further delineate the relationships among variables relevant to international student adjustment, leaders in the field have called for increased focus on the development of institutional support for the academic and cultural transition of international students (Sam \& Berry, 2010; Smith \& Khawaja, 2014). The current study was designed to address this call by examining the efficacy of an academic and cultural transition course to teach international students intercultural skills and how to use them in university contexts in the US. Additionally, the results provide an initial exploration of the potential of such courses to increase students' sense of campus belonging and social support.

\section{LITERATURE REVIEW}

Within the host society, the university setting is critical for the well-being of incoming international students as it is designed to provide students tools and opportunities to succeed. Faculty and staff at universities have responded to international student needs by providing cultural transition programming, including intentional roommate pairings, enhanced orientations, bridging programs, and semester courses designed specifically to address transition strengths, skills, and challenges (Smith \& Khawaja, 2014; Tolman, 2017). Because students traveling abroad to study prefer to receive college credit (Doyle et al., 2010) and because semester courses span a longer timeframe than orientation programs, semester courses represent an important opportunity to facilitate foreign students' adjustment to US universities (Kovtun, 2011).

The authors of the current study located three published studies which examined the impact of cultural transitions courses on international student adjustment to US universities (Andrade, 2006b; Andrade, 2009; Kovtun, 
2011). Each study documented positive academic or social outcomes for students taking an academic and cultural transition course. Andrade (2006b) investigated students' perceptions of the relative importance of the various elements of the course content, which included: policies and procedures of the English as a Second Language program and the university, campus resources, time management, study skills, American university classroom culture, American appreciation of cultural diversity, and regional history and culture. Students perceived the following aspects of the course to be most useful: information about the host culture, information about the university expectations and social norms, and experience of active learning strategies and group-work (Andrade, 2006b). In a follow-up study, Andrade (2009) documented increases in students' $(n=40)$ familiarity with course elements noted above from pre- to post-course. Students reported significant increases in comfort level of interacting with faculty members, but did not report similar increases in comfort level of interacting with students of other cultures. Kovtun (2011) reported that students $(n=19)$ who completed the first-year cultural transition seminar course perceived significant increases in their writing and presentation abilities as well as a higher comfort level with people of diverse races and orientations.

Additional research on short-term transition courses for international students has taken place in Australia, with positive findings documented for the socio-cultural skills training program, Excellence in Cultural Experiential Learning and Leadership (EXCELL; Mak, Barker, Logan, \& Millman, 1999), as well as the Strengths, Transitions, Adjustments, and Resilience program designed to enhance international student emotional coping (STAR; Smith \& Khawaja, 2014). Mak and Buckingham (2007) documented increases in social interaction with students of other cultures for students participating in the EXCELL program compared to students in a control group. STAR program findings revealed increases in student perceived coping self-efficacy and psychological adaptation; however, only $25 \%(n=4)$ of the sample were first-year international students (Smith \& Khawaja, 2014).

\section{Campus Belonging and Social Support}

Campus belonging and social support represent two important socioemotional outcomes for international students during their transition to US universities (Smith \& Khawaja, 2011). The degree to which students sense they belong in their university campus and are accepted by the campus community is related to mental health and depression (Atri, Sharma, \& Cottrell, 2007) and academic persistence (e.g., continuing toward degree 
completion rather than dropping out; Mamiseishvili, 2012). International students' campus belonging can be positively influenced by their home institution, as students reported an increased sense of campus belonging when they participated in leadership programs that emphasized teamwork, courses that elicited dialogue between students of many cultures, and activities that were reflective of their home culture (Glass, 2012). An important next step for researchers is to determine whether intercultural skills taught in an academic and cultural transition course can lead to increased campus belonging.

Students' perceptions of social support can influence their academic and socio-emotional outcomes, including academic achievement (Bai, 2016), academic stress (Misra, Crist, \& Burant, 2003), and acculturative stress (Poyrazli, Kavanaugh, Baker, \& Al-Timimi, 2004; Sullivan \& KashubeckWest, 2015). To the authors' knowledge, only one previous study has documented increases in perceived social interaction for international students taking a cultural transition course (Mak \& Buckingham, 2007). However, the authors were unable to locate any studies which document linkages between international undergraduate student participation in an academic and cultural transition course in the US and their perceptions of belonging and social support. The current study was designed to test for these relationships.

\section{THEORETICAL FRAMEWORK}

In contrast to the construction of existing cultural transition courses based on student retention frameworks (Andrade, 2006b, 2009) or an intersection of three transition and cross-cultural theories (Kovtun, 2011), the semesterlong course in the current study used the relative acculturation extended model (RAEM; Navas et al., 2005) as its guiding framework. The RAEM is designed to highlight how successful navigation of intercultural contexts requires different behaviors and attitudes based on the specific context. For instance, the attitudes, behaviors, and norms needed for academic success in US university classrooms might be very different than those needed to navigate issues with roommates in the US university dorm room. In accordance with the RAEM, academic or social interaction with students and professors were examined in the settings most frequented by first-year students, including the classroom, the dorm room, and other social settings. The RAEM aligns with Acculturation Theory, as Sam and Berry (2010) note the importance of being able to replicate culturally-specific behaviors in different contexts. Prior research suggests the importance of international 
students' ability to communicate with peers, roommates, and professors both inside and outside of the classroom (Arasaratnam \& Doerfel, 2005; Gebhard, 2012; Lee \& Ciftci, 2014). Additionally, student acquisition and mastery of the English language - both spoken and written - is an important factor to first-year international students' adjustment (Andrade, 2006b); thus, course content included academic writing support. However, the current study focuses on students' intercultural skills development, perceived campus belonging, and perceived social support.

Table 1. Content outline of the academic and cultural transition core curriculum.

\begin{tabular}{lll}
\hline Themes & Content & Targeted outcomes \\
\hline Cultural & Levels of culture & Intercultural competence \\
Framework & American cultural profile & \\
and Cultural & Iceberg theory of culture & \\
Awareness & Culture scales
\end{tabular}

Academic Describe, analyze, interaction evaluate

Groupwork norms

Resolving conflict

Communicating with faculty

Interacting with library research staff

Social American social life interaction

College social norms

Navigating roommate issues
Suspending judgment

Shifting perspectives

Self-advocacy

Interacting in class with students of other cultures

Communicating with professors

Communicating with students from other cultures

Making friends with students from other cultures

Solving problems with roommates

The primary goal for students in the academic and cultural transition course was to become knowledgeable about and confident in using three intercultural skills identified as critical for navigating cross-cultural situations (shifting perspective, suspending judgment, and self-advocating; 
Deardorff, 2006) in the different US university contexts in which first-year students typically experience the greatest challenges. These challenging contexts include: interacting with other students in class (Gebhard, 2012; Tian \& Lowe, 2009), communicating with faculty (Poyrazli \& Grahame, 2007), navigating roommate differences (Erb, Renshaw, Short, \& Pollard, 2014; Yao, 2016), and communicating and making friends with students of other cultures (Gareis, 2012; Longerbeam, DeStefano, \& Lixin, 2013). Thus, the core curriculum in all sections of the course centered on intercultural skill development in academic and social contexts. See Table 1 for a detailed overview of core course curriculum. Secondary goals of the course were for students to become more connected to their campus community and build socially supportive relationships with faculty, staff, and peers.

\section{RESEARCH METHOD}

\section{Recruitment and Survey Administration Timeline}

The current study took place at a mid-sized private university in the Southeast US with an undergraduate international student population of roughly ten percent of the student body. The authors were granted approval by the Institutional Review Board prior to enrollment of participants. Participants were either (a) students taking an academic and cultural transition course (i.e., the intervention group), or (b) international students at the university not taking the course (i.e., the comparison group).

\section{Intervention Group Recruitment}

International students taking the one-credit academic and cultural transition course in the fall of 2015 or fall of 2016 were invited to participate in the research study intervention group. Of the 51 students enrolled in the courses, $43(82.35 \%)$ consented to participate in the study.

Confidentiality and anonymity of students in the intervention group were maintained through the following protocol: the first author, second author, and the additional faculty member co-teaching the four sections of the course were blind to which students participated in the study until after the semester was complete and student grades were turned in. The third author, a graduate student not involved in the course instruction invited students in the academic and cultural transition course to participate in the study. The third author also administered the surveys to the students in the course who chose to participate in the study. Within two hours of each data collection, the third author created a password-protected digital file containing student names and study identification numbers; she then de- 
identified the surveys by replacing student names with their study identification number.

Participation in the intervention group included enrollment in the cultural transition course and the completion of two surveys: one during the first five weeks of the semester course (T1), and the other after the completion of the course in the winter of 2015 (T2). The third author consented participants and administered the surveys during the last twenty minutes of a class session, when the course instructors had left the room. The first survey was administered between weeks four and five in the course, so that students would have the opportunity to experience some of the contexts and outcomes of interest (e.g., communicating with professors). Students received no incentive for their participation in the study. Of the 43 participants, 42 (97.67\%) completed both the fall (T1) and the winter (T2) surveys. The unusually high participation and completion rate may be explained by the provision of class time for students to complete the surveys.

\section{Comparison Group Recruitment and Procedure}

A survey was distributed via email at the end of the fall semester in 2016 to all the international students at the university who did not take the course. The survey assessed their perceptions of the academic and social experience. Of the 421 undergraduate international students who received the survey, $32(7.60 \%)$ completed the survey, which included demographic, belonging, and social support measures. The low participation rate in the comparison group survey may be due to student fatigue at the end of the semester during exam time.

\section{Participants}

Demographic information for intervention group and comparison group participants is listed in Table 2. Chinese students (85.71\%) and male students $(54.77 \%)$ were over-represented in the intervention group compared to both the international student body of the institution and the comparison group.

\section{Course Structure}

Four sections of the academic and cultural transition course were taught between fall 2015 and fall 2016. All four sections included the international transition core curriculum delineated in Table 1. Each classroom contained up to 24 seats, desks or tables for students, and a projector. A checklist was completed for each of the components of the core curriculum, and $100 \%$ of the core curriculum was taught across all four sections. Each of the four 
sections included additional curriculum which was differentiated to provide unique support to students. The faculty members and the additional curricular foci of each course section is listed in Table 3.

An analysis of variance (ANOVA) was conducted to test whether the different additional curricular pieces influenced student learning outcomes, perceptions of belonging, and perceptions of social support; no differences were detected between sections, suggesting it was appropriate to treat the four sections as one sample receiving the core curriculum of the course as an intervention.

Table 2. Intervention and comparison group demographic data.

\begin{tabular}{lcclcc}
\hline $\begin{array}{l}\text { Intervention } \\
\text { Group }(n=42)\end{array}$ & $n$ & $\%$ & $\begin{array}{l}\text { Comparison } \\
\text { Group }(n=32)\end{array}$ & $n$ & $\%$ \\
\hline Gender & & & Gender & & \\
$\quad$ Female & 19 & 45.23 & Female & 20 & 62.50 \\
Male & 23 & 54.77 & Male & 10 & 31.25 \\
& & & N/A & 2 & 6.25 \\
Year & & & Year & & \\
1 & 41 & 97.62 & 1 & 11 & 34.38 \\
2 & 1 & 2.38 & 2 & 8 & 25.00 \\
3 & 0 & 0 & 3 & 5 & 15.63 \\
$4+$ & 0 & 0 & $4+$ & 5 & 15.63 \\
Citizenship & & & Citizenship & & \\
China & 36 & 85.71 & China & 23 & 71.87 \\
France & 2 & 4.76 & Canada & 2 & 6.25 \\
Egypt & 1 & 2.38 & India & 1 & 3.13 \\
Germany & 1 & 2.38 & Italy & 1 & 3.13 \\
Russia & 1 & 2.38 & South Korea & 1 & 3.13 \\
Uzbekistan & 1 & 2.38 & UK & 1 & 3.13 \\
\hline
\end{tabular}

Students received one hour of credit for the course, which met for one hour once a week for fifteen weeks during the fall semester of the participants' first year at the institution. The course content centered on the RAEM model (Navas et al., 2005), wherein intercultural skills are enacted differently depending on context. Participants learned intercultural 
competence skills (e.g., perspective shifting, suspending judgment, selfadvocacy) as well as how to use them in critical contexts for academic and social success at US colleges and universities. Detailed course materials are available upon request from the first author.

\section{Measures}

The intervention group participant survey included all measures at $\mathrm{T} 1$ and T2. The comparison group survey was distributed at T2 (winter), and included three measures: demographic information, perceived social support, and perceived belonging.

\section{Demographic Information}

The survey included items on student gender, year at university, and country of citizenship. Demographic information was collected from the intervention group at $\mathrm{T} 1$ and from the comparison group at $\mathrm{T} 2$.

Table 3. Academic and cultural transition course sections and additional foci.

\begin{tabular}{llllcl}
\hline Section & Year & $n$ & Faculty & $\begin{array}{l}\text { Core } \\
\text { taught }\end{array}$ & Additional curriculum \\
\hline A & 2015 & 15 & First author & $100 \%$ & $\begin{array}{l}\text { Academic writing } \\
\text { Sports, media, politics }\end{array}$
\end{tabular}

B $\quad 2015 \quad 13$ Second author $\quad 100 \% \quad$ Academic writing Sports, media, politics Identity

$\mathrm{C}$

$2016 \quad 7 \quad \begin{aligned} & \text { First author } \\ & \text { and additional }\end{aligned}$

$100 \% \quad$ Academic writing faculty member

$\mathrm{D}$

$2016 \quad 7 \quad \begin{aligned} & \text { First author } \\ & \text { and additional } \\ & \text { faculty member }\end{aligned}$

$100 \% \quad$ Academic writing faculty member 


\section{Perceived Knowledge, Confidence, and Usefulness of Transition concepts and Skills}

The nine-item knowledge, confidence, and usefulness (KCU) survey was adapted from Lane, Menzies, Bruhn, and Crnobori (2011) to assess increases in student perceived knowledge of, perceived confidence in using, and perceived usefulness of skills and concepts central to the transition into US university academic and social life. The KCU survey was selected as it assesses the three areas (i.e., knowledge, confidence, and perceived usefulness) that are critical for the adoption of new attitudes and behaviors, and because it has been adapted successfully for other short- and mediumlength courses and professional development (Brunsting et al., 2017). For each of the nine skills or concepts, students indicated their knowledge of a particular skill/concept on a four-point Likert-type scale anchored at 0 (I have no knowledge of this concept or skill) and 3 (I have a substantial amount of knowledge about this concept or skill). The next response option assessed their confidence in using the skill concept on the same four-point Likert-type scale with similar labels (e.g., $0=\mathrm{I}$ am not confident in my ability to use this concept or skill; $3=$ I am very confident in my ability to use this concept or skill) followed by a response signifying their perceived usefulness of the skill or concept with similar labels (e.g., $0=\mathrm{I}$ do not believe this concept or skill is useful; $3=\mathrm{I}$ believe this concept or skill is very useful). Students rated their perceived knowledge, confidence, and usefulness of intercultural competence as well as specific skills (e.g., perspective taking, suspending judgment, self-advocating) that typically increase one's intercultural competence. For example, students rated their perceived knowledge of perspective taking, their perceived confidence in being able to perspective take, and their perceived usefulness of perspective taking.

Reliability of the adapted KCU measure was assessed through correlations between knowledge and confidence ratings on each item; usefulness is not included, as one can have little knowledge or confidence in a skill but perceive it to be useful. Correlations between knowledge and confidence ratings for each of the nine skills/contexts ranged from .66 to .81 for the fall survey and from .41 to .72 on the winter survey. Some items from the adapted KCU measure were first piloted in 2015, with correlations between knowledge and confidence ranging from .63 to .80 . Face validity of the adapted KCU measure was derived from an application of the RAEM model (Navas et al., 2005) to the research literature on contexts in which international students struggle. As noted in the limitations, additional studies are needed to test for validity of the KCU measure for intercultural skills. 


\section{Perceived Social Support}

Perceived social support was assessed using the satisfaction subscale from the Social Support Questionnaire (SSQ; Sarason, Sarason, Shearin, \& Pierce, 1987). The six-item subscale provides information regarding individuals' perceptions of the social support they receive from people in their immediate environment (e.g., friends, peers, professors). The SSQ satisfaction subscale has been documented to have high internal consistency $(\alpha=.79)$. The subscale has been slightly adapted for phrasing so that all items begin with the statement stem: "My friends, peers, professors, and staff..." Examples of statements include: "My friends, peers, professors, and staff help me feel more relaxed when I am stressed" and "My friends, peers, professors, and staff are dependable when I need help" Students report the degree to which they agree with each statement on a five-point Likert-type scale $(0=$ strongly disagree, $1=$ somewhat disagree, $2=$ neither agree nor disagree, $3=$ somewhat agree, and $4=$ strongly agree) .

\section{Perceived Belonging}

Perceived belonging was assessed by the six-item Campus Climate Scale (Glass, 2012). Example items include "I see myself as part of the campus community" and "I feel that I am a member of the campus community". Students indicated the degree to which they agree with each item on a five-point Likert-type scale $(0=$ strongly disagree, $1=$ somewhat disagree, $2=$ neither agree nor disagree, $3=$ somewhat agree, and $4=$ strongly agree). The campus climate scale has been documented to have high internal consistency ( $\alpha=.83$; Glass, 2012).

\section{Social Validity Questions}

Social validity of the course was assessed at T2. Two Likert-type questions were asked to gauge student agreement or disagreement with the following statements: "this course helped me in my academic courses here on campus" and "this course has helped me in social interactions here on campus".

\section{Data Analysis}

After screening the data and testing for assumptions of univariate and multivariate normality, analyses were conducted to check for pre-existing differences among demographic groups. In order to answer the first research question, paired $t$-tests were examined that compared student knowledge of, confidence in, or perceived usefulness of intercultural competence, three core intercultural skills, and their abilities to navigate five critical university 
contexts from fall to winter. Effect sizes were calculated for significant comparisons. To answer the second research question, regression analyses were calculated to examine whether there was a significant difference between participants and comparison group on perceived belonging and social support, controlling for demographic factors. Means were calculated for social validity scores.

The following hypotheses were proposed:

$\mathrm{H}_{1}$ : Students who complete the academic and cultural transition course will report significant increases in perceived knowledge, confidence, and usefulness of core intercultural skills and their applicability in specific US university contexts.

$\mathrm{H}_{2}$ : Students who complete the academic and cultural transition course will report significantly higher campus belonging and social support compared to students who did not take the course.

\section{RESULTS}

\section{Test of Assumptions and Measurement Reliability}

Tests were calculated for violations of univariate and multivariate normality: no items exceed standards for skewness (+/- 2) or kurtosis $(+/-5$; Bowen \& Guo, 2012; Ware, Ferron, \& Miller, 2013; West, Finch, \& Curran, 1995). Mahalanobis' distances were inspected, and no multivariate outliers were identified. Measurement reliability was assessed with Cronbach's alpha. Perceived social support had high internal consistency at T2 $(\alpha=.89)$, exceeding the internal consistency reported by Sarason et al. $(1987 ; \alpha=.79)$. Perceived campus belonging also demonstrated high reliability at T2 $(\alpha=$ .82).

\section{Preexisting Differences}

No significant pre-existing differences were found on demographic variables for either the participant sample or the comparison group sample. Due to small sample sizes of subgroups, the acceptance of the null hypothesis should be taken as just that: there is not strong enough evidence to support pre-existing differences. 


\section{Intervention Group Sample}

Two one-way ANOVAs were calculated, one to test for gender differences and one to test for differences of country of origin (China v. non-China) in outcomes on all eleven variables of interest at T1 and T2 (i.e., the nine intercultural skills, campus belonging, and social support) with no significant differences. A Holm-Bonferonni correction was implemented to account for familywise error rate due to multiple tests for significance. Holm-Bonferonni orders the probability values from least to greatest, and tests each one against and adjusted alpha (Holm, 1979). Thus, the lowest pvalue would need to be less than $.0022(.05 / 22)$, and the next lowest would need to be less than $.0024(.05 / 21)$ to be considered statistically significant. Only one variable approached significance, with women reporting greater perceived knowledge, confidence, and usefulness of making friends with American students $(F[1]=4.64, p=.04)$.

\section{Comparison Group Sample}

A one-way ANOVA was conducted to test for potential influence of student year on the outcome variables campus belonging and social support. The ANOVA was non-significant for both campus belonging $(F[1,28]=$ $2.48, p=.07)$ and social support $(F[1,28]=2.09, p=.12)$, meaning that the first-year students' scores were not significantly different from those of other years.

\section{Differences in Learning Outcomes from $\mathrm{T} 1$ to $\mathrm{T} 2$}

\section{Perceived KCU of Intercultural Skills in Context}

The results of the paired t-tests for differences in student knowledge, confidence, and usefulness of the nine skills and efficacy in specific university contexts targeted by the course content are displayed in Table 4 . Again, the Holm-Bonferroni correction (Holm, 1979) was implemented, with an initial level of significance of $.0019(.05 / 27)$ for the result with the lowest $p$-value. At the completion of the course, students reported significantly greater knowledge for four of the nine skills and contexts, significantly greater confidence for four of the nine skills and contexts, and significantly greater usefulness for one of the nine skills and contexts. Effect sizes for these increases ranged from medium to large $(d=0.55$ to 0.87$)$ based on Cohen's (1988) suggested criteria: low $=0.2$, medium $=0.5$, large $=0.8$. 
Table 4. Two-tailed paired t-tests of mean difference of perceived knowledge, competence, and usefulness of student learning outcomes from fall to winter on a four-point (0-3) scale.

\section{$\Delta M$}

Fall Spring (T2-

$\begin{array}{lll}M & M & \mathrm{~T} 1)\end{array}$

T1) $\quad$ Paired $t$-test $\quad p \quad d$

Intercultural competence

$\begin{array}{lllllll}\text { Knowledge } & 1.88 & 2.36 & 0.48 & t(41)=3.37 & .002^{*} & 0.68 \\ \text { Confidence } & 1.95 & 2.36 & 0.41 & t(41)=3.95 & .000^{*} & 0.55 \\ \text { Usefulness } & 2.29 & 2.60 & 0.31 & t(41)=2.17 & .036 & \end{array}$

Suspending judgment

$\begin{array}{lllllll}\text { Knowledge } & 1.90 & 2.51 & 0.61 & t(40)=4.02 & .000^{*} & 0.87 \\ \text { Confidence } & 1.97 & 2.56 & 0.59 & t(38)=3.71 & .001^{*} & 0.84 \\ \text { Usefulness } & 2.56 & 2.72 & 0.15 & t(38)=1.43 & .160 & \end{array}$

Shifting Perspectives

$\begin{array}{lllllll}\text { Knowledge } & 2.19 & 2.55 & 0.36 & t(41)=2.82 & .007 & 0.57 \\ \text { Confidence } & 2.15 & 2.58 & 0.42 & t(39)=3.44 & .001 * & 0.65 \\ \text { Usefulness } & 2.50 & 2.70 & 0.20 & t(39)=2.13 & .118 & \end{array}$

Self-advocacy

$\begin{array}{lllllll}\text { Knowledge } & 1.93 & 2.34 & 0.42 & t(40)=3.18 & .003^{*} & 0.63 \\ \text { Confidence } & 2.02 & 2.49 & 0.46 & t(40)=3.53 & .001^{*} & 0.69 \\ \text { Usefulness } & 2.41 & 2.68 & 0.27 & t(40)=2.42 & .020 & \end{array}$

Interacting in class with students from other cultures

$\begin{array}{llllll}\text { Knowledge } & 2.21 & 2.55 & 0.33 & t(41)=2.55 & .014 \\ \text { Confidence } & 2.20 & 2.49 & 0.29 & t(40)=2.08 & .044\end{array}$




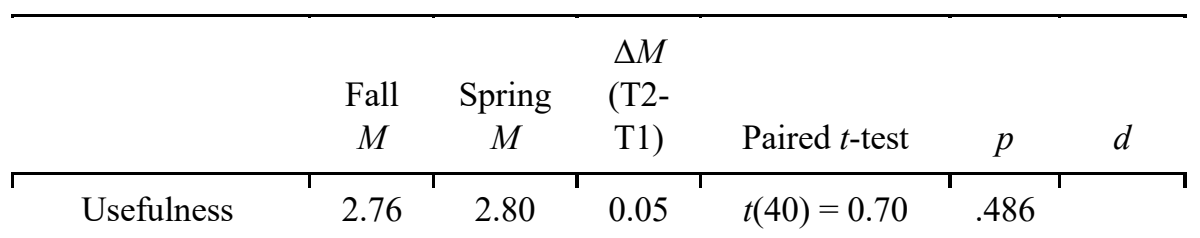

Communicating with students from other cultures

$\begin{array}{lcccccc}\text { Knowledge } & 2.14 & 2.62 & 0.48 & t(41)=4.37 & .000^{*} & 0.77 \\ \text { Confidence } & 2.12 & 2.55 & 0.43 & t(41)=3.13 & .003^{*} & 0.58 \\ \text { Usefulness } & 2.79 & 2.76 & -0.02 & t(41)=-0.30 & .800 & \end{array}$

Making friends with students of other cultures

$\begin{array}{llllll}\text { Knowledge } & 2.17 & 2.52 & 0.36 & t(41)=2.82 & .007 \\ \text { Confidence } & 2.05 & 2.36 & 0.31 & t(41)=2.80 & .008 \\ \text { Usefulness } & 2.71 & 2.71 & 0.00 & t(41)=0.00 & 1.00\end{array}$

Solving problems with roommates

$\begin{array}{lllllll}\text { Knowledge } & 2.34 & 2.63 & 0.29 & t(40)=2.22 & .032 & \\ \text { Confidence } & 2.45 & 2.65 & 0.20 & t(39)=1.67 & .103 & \\ \text { Usefulness } & 2.41 & 2.78 & 0.37 & t(40)=3.35 & .002 * & 0.70\end{array}$

Communicating with professors

$\begin{array}{llllll}\text { Knowledge } & 2.29 & 2.55 & 0.26 & t(41)=1.98 & .054 \\ \text { Confidence } & 2.32 & 2.51 & 0.20 & t(40)=1.48 & .146 \\ \text { Usefulness } & 2.90 & 2.85 & -0.05 & t(40)=-0.70 & .486\end{array}$

$\overline{\text { Note. } * \text { indicates a statistically significant } t \text {-test. Effect sizes were calculated }}$ for significant comparisons. Holm-Bonferonni corrections (Holm, 1979) were calculated to account for multiple comparisons. The last significant 
comparison was Confidence of Communicating with other students $(p=$ $.003 ; \alpha=.003[.05 / 17])$.

\section{Differences in Perceived Campus Belonging and Social Support at T2}

\section{Perceived Campus Belonging}

A linear regression was conducted to determine whether participation in the academic and cultural transition course influenced student campus belonging at $\mathrm{T} 2$, controlling for gender and whether or not students were from China. A non-significant regression equation was documented $(F[3,67]$ $=2.63, p=.057$ ) with an $\mathrm{R}^{2}$ of .11 . However, student campus belonging was significantly predicted by participation in the academic and cultural transition course. Participation in the academic and cultural transition course accounted for an increase of 0.35 in student perceived belonging on a fourpoint scale, with a medium effect size $(d=.55)$. See Table 5 for results.

Table 5. Perceived campus belonging in winter (T2) predicted by participation in course, gender, and Chinese citizenship status.

\begin{tabular}{lccc} 
Construct & $\mathrm{B}$ & $S E$ B & $\beta$ \\
\hline Constant & 2.76 & .32 & \\
Gender & .15 & .16 & .11 \\
Chinese & -.20 & .21 & -.14 \\
Participant in course & .35 & .16 & $.26^{*}$ \\
\hline
\end{tabular}

Note. $* p<.05$

\section{Perceived Social Support}

Linear regression results were examined to determine whether participation in the course was associated with an increase in perceive social support at $\mathrm{T} 2$, controlling for gender and nationality. A non-significant regression equation was documented $(F[3,66]=2.14, p=.10)$ with an $\mathrm{R}^{2}$ of .09 . However, perceived social support was significantly predicted by participation in the academic and cultural transition course. Participation in the academic and cultural transition course accounted for an increase of 0.43 in student campus belonging with a medium effect size $(d=.54$; see Table $6)$. 
Table 6. Perceived social support in winter (T2) predicted by participation in course, gender, and Chinese citizenship status

\begin{tabular}{lccc}
\hline Construct & $\mathrm{B}$ & $S E$ B & $\beta$ \\
\hline Constant & 2.55 & .40 & \\
Gender & .16 & .20 & .10 \\
Chinese & .07 & .26 & .03 \\
Participant in course & .43 & .20 & $.26^{*}$ \\
\hline
\end{tabular}

Note. ${ }^{*} p<.05$

\section{Social Validity}

Student quantitative reports of their satisfaction with the course were generally positive, scoring above the agree anchor $(M=4.04$, scale $=1-5)$ on the item this course helped me in my academic courses and at the agree anchor $(M=4.00)$ on the item this course helped me in my social interactions.

\section{DISCUSSION}

Participants in the academic and cultural transition course reported increases in knowledge of, confidence in, and/or usefulness of intercultural competence, three core intercultural skills (suspending judgment, shifting perspectives, and self-advocacy), and three of the five abilities in US university contexts. Thus the first hypothesis was partially supported. The results of the study provide initial evidence that a one-hour semester course at a US university can promote increases in first-year international undergraduate student perceived intercultural competence, including specific skills such as suspending judgment and shifting perspectives. This is an important finding, as it extends the current literature on transition courses for first-year international students at US universities, which have focused on increasing student cultural knowledge and understanding of university policies (Andrade 2006b, 2009) as well as writing and presentation skills (Kovtun, 2011).

With regard to students' abilities to successfully navigate US university contexts in which international students - and domestic students - often struggle, the findings from the current study are somewhat mixed. Students gained in knowledge and confidence of how to communicate with students of other cultures outside of the classroom; however, they did not express gains in ability to make friends or solve problems with roommates. It is possible that one semester does not constitute enough time for students to 
feel significantly more confident to make a close friend or to solve problems with roommates. Another possibility is that students first need to become more confident in their communication with students of other cultures before they are able to make lasting friendships or resolve issues with roommates. Previous studies of cultural transitions courses documented increases in communicating with faculty (Andrade, 2009) and comfort interacting with students of other cultures (Kovtun, 2011); the current study adds communication with students of other cultures to the positive outcomes of academic and cultural transitions courses.

There was only one significant increase in students' perception of the usefulness of the intercultural skills and contexts: solving issues with roommates. However, students rated most skills and contexts as highly useful in the fall survey, leaving little room for an increase in the winter survey. It appears that the students taking the course underestimated the amount of issues they would encounter with roommates, which coincides with findings of Yao (2016) at a midwestern public university.

\section{Perceived Campus Belonging and Social Support}

Student campus belonging predicts a range of important academic and social outcomes and represents a potential target for interventions and mediation analyses (Atri, Sharma, \& Cottrell, 2007; Mamiseishvili, 2012). Results of the current study supported the second hypothesis, revealing that students who completed the academic and cultural transition course during their first year at the university reported significantly higher perceived campus belonging and social support than did students who did not participate in the course. Both findings are novel and extend prior research documenting increased student social interaction following a cultural transition course in Australia (Mak \& Buckingham, 2007). It is critical to continue to conduct intervention research given the far-reaching academic, social, and emotional correlates and outcomes of social support and belonging.

\section{Limitations}

The authors acknowledge some notable limitations of the current study. First, the study did not have a control group, but rather a comparison group as students did not receive random assignment to the intervention course as the course is an elective course. Second, the total sample size $(N=74)$ is small and derived from students at one university, meaning the study is limited in its generalizability. The low response rate for the comparison group limits generalizability as well. The authors recommend developing a 
more robust recruitment plan for a comparison group in future studies. Third, although the course core curriculum was taught in all four sections, each section featured different additional information which could influence student outcomes. This limitation was mitigated to a degree by testing for differences in outcomes between students in the four sections-no significant differences were found. Fourth, the participant sample was overrepresented with students from China. Additional data from a more diverse international student sample is needed. Fifth, the aggregation of nonChinese students into one group for regression analyses is problematic given cultural differences between students across the globe. However, given that Chinese students currently comprise the majority of international students at many US institutions of higher education, it is valuable to understand how test for differences in outcomes whenever possible. Sixth, only partial reliability and validity data for the adapted KCU measure is available. It would be preferable to have a direct measure of student knowledge of certain skills and contexts to provide convergent validity.

These limitations indicate that the results of this study should be interpreted with caution. Replication with a more diverse sample at multiple universities is needed. Acknowledging these limitations, the authors intend the current study to serve as initial evidence to suggest the potential for participation in an academic and cultural transition course to increase firstyear international students' intercultural skills in context and to enhance their perceived belonging and social support.

\section{IMPLICATIONS}

A successful transition into a new cultural milieu depends on many factors, especially social inclusion. Educational administrators should consider an array of practices to foster inclusion in student life and social organizations, academic and co-curricular activities and personnel, and offices and staff throughout the institution. Given the social and interactional nature of the skills and attitudes encompassed under the rubric of intercultural competency, it is not surprising that students who completed a course focused on increasing intercultural competence reported higher belonging and social support than students who did not take the course.

Timing is also critical to consider. Four weeks into their first semester, students in the course did not see the ability to navigate roommate issues as important as they did at the end of the first semester. It may be that residence life trainings, check-ins, or interventions include a follow-up session at the beginning of the second semester. Given the results of a recent 
study (Tolman, 2017) documenting positive roommate-pairing intervention effects for international first-year students paired with upperclassmen US students compared to international first-year students paired with first-year US students, we should consider a wide range of approaches.

It is important to remember that the host culture at institutions of higher education will influence international student adjustment. International students may seek to develop strong intercultural skills and seek social integration; however, if the primary gatekeepers of campus culture expect international students to assimilate or to accept marginalization, then successful pursuit of inclusion and social integration may be difficult or impossible (Berry, 2005). Thus, faculty, staff, and administrators at institutions of higher education should also consider ways in which to support the intercultural competence of all members of the university who influence the campus culture.

\section{Future Research Directions}

The present research provides preliminary evidence that first-year international students increase their intercultural skills through participation in an academic and cultural transition course. The field would benefit from replication of these findings with larger sample sizes and examination of longitudinal effects of the first-year seminar by comparison to a control group. As expressed by the student participants in the present study and those in previous research, first-year seminar instruction for international students should evolve to include further opportunities for interaction with domestic students (Andrade, 2009) and for academic writing preparation (Kovtun, 2011).

It is important to further explore the factors that influence international student belonging at US universities. Glass (2012) documented linkages between perceived belonging and (a) the number academic terms in which students took courses that had an opportunity for dialogue between people with various viewpoints, (b) the number academic terms in which students participated in leadership opportunities, and (c) the number of academic terms in which students participated in events focused on their cultural heritage. This study adds the connection between participation in a cultural transition course and their sense of belonging. Future research is needed to test whether international students graduating high school in the US have higher levels of belonging than those who graduate in their home countries and whether various sources of social support (e.g., friends, peers, faculty) differentially influence student belonging. 
In order to better understand international students' perceptions of social support, sources of perceived social support should be assessed separately in future research. One recent study (Bochhibhoya, Dong, \& Branscum, 2017) has assessed multiple sources of social support, but the sample does not disaggregate results for undergraduate students from their total student sample, making interpretation difficult given the differences in undergraduate and graduate student experiences. Such data would inform the development of specific course content for fostering meaningful relationships between international students and each of the university community members with whom they will interact, which could help to attenuate the sociocultural distress international students experience (Smith \& Khawaja, 2014). Finally, while socioemotional adjustment is an important factor in the first-year international student experience, it is important to investigate whether a relationship exists between academic achievement outcomes and participation in transition courses.

\section{CONCLUSION}

Most undergraduate international students face challenges adjusting to US universities during their first year. Although domestic students encounter similar obstacles, international students' lack of familiarity with culturally-appropriate behaviors in specific university contexts can make the task more daunting. One approach with a growing base of evidence for helping international students to meet these academic, cultural, and social challenges through enrollment in an academic and cultural transition course. The current study reveals that first-year undergraduate international students taking the course gained intercultural skills and confidence in navigating university settings. They also experienced higher belonging and social support at their institution compared to students who did not take the course. These findings are encouraging, but there is much more that needs to be researched to help international undergraduate students successfully adjust to US universities.

\section{REFERENCES}

Andrade, M. S. (2006a). International students in English-speaking universities: Adjustment factors. Journal of Research in International Education, 5, 131-154.

Andrade, M. S. (2006b). A first-year seminar for international students. Journal of the First-year Experience \& Students in Transition, 18, 85-103. 
Andrade, M. S. (2009). The value of a first-year seminar: International students' insights in retrospect. Journal of College Student Retention, 10, 483-506.

Arasaratnam, L. A., \& Doerfel, M. L. (2005). Intercultural communication competence: Identifying key components from multicultural perspectives. International Journal of Intercultural Relations, 29, 137-163.

Atri, A., Sharma, M., \& Cottrell, R. (2007). Role of social support, hardiness, and acculturation as predictors of mental health among international students of Asian Indian origin. International Quarterly of Community Health Education, 27, 59-73.

Bai, J. (2016). Perceived support as a predictor of acculturative stress among international students in the United States. Journal of International Students, 6, 93-106.

Berry, J. W. (2005). Acculturation: Living successfully in two cultures. International Journal of Intercultural Relations, 29, 697-712.

Bhochhibhoya, A., Dong, Y., \& Branscum, P. (2017). Sources of social support among international college students in the United States. Journal of International Students, 7, 671-686.

Bowen, N. K., \& Guo, S. (2012). Structural Equation Modeling. New York: Oxford University Press.

Brunsting, N. C., Smart, J. W., Eisner, J., Liu, J., Coverdell, T., \& Sun, W. (2017). Arrive prepared: An academic and cultural transition (ACT) program for precollege international students. E-Source for College Transitions, 15(1), 9-12.

Cohen, J. (1988). Statistical power analysis for the behavioral sciences. Hillsdale: Lawrence Erlbaum.

Deardorff, D. K. (2006). Identification and assessment of intercultural competence as a student outcome of internationalization. Journal of Studies in International Education, 10, 241-266.

Doyle, S., Gendall, P., Meyer, L. H., Hoek, J., Tait, C., McKenzie, L., \& Loorparg, A. (2010). An investigation of factors associated with student participation in study abroad. Journal of Studies in International Education, 14, 471490.

Erb, S. E., Renshaw, K. D., Short, J. L., \& Pollard, J. W. (2014). The importance of college roommate relationships: A review and systematic conceptualization. Journal of Student Affairs Research and Practice, 51, 43-55.

Gareis, E. (2012). Intercultural friendship: Effects of home and host region. Journal of International and Intercultural Communication, 5, 309-328.

Gebhard, J. G. (2012). International students' adjustment problems and behaviors. Journal of International Students, 2, 184-193.

Glass, C. R. (2012). Educational experiences associated with international students' learning, development, and positive perceptions of campus climate. Journal of Studies in International Education, 16, 228-251. 
Holm, S. (1979). A simple sequentially rejective multiple test procedure. Scandinavian Journal of Statistics, 6, 65-70.

Kovtun, O. (2011). International student adaptation to a U.S. college: A mixed methods exploration of the impact of a specialized first-year course at a large Midwestern institution. Journal of Student Affairs Research and Practice, 48, 349-366.

Lane, K. L., Menzies, H. M., Bruhn, A. L., \& Crnobori, M. (2011). Managing challenging behaviors in schools: Research-based strategies that work. New York: Guilford.

Lee, J., \& Ciftci, A. (2014). Asian international students' socio-cultural adaptation: Influence of multicultural personality, assertiveness, academic selfefficacy, and social support. International Journal of Intercultural Relations, 38, 97-105.

Longerbeam, S. D., DeStefano, T. J., \& Lixin, Y. (2013). "We cannot reach them": Chinese undergraduate student perceptions of the U.S. campus climate. Journal of Student Affairs Research and Practice, 50, 326-344.

Mak, A. S., Barker, M., Logan, G., \& Millman, L. (1999). Benefits of cultural diversity for international and local students: Contributions from an experiential social learning program (The EXCELL Program). In D. Davis \& A. Olsen (Eds.), International education: The professional edge (pp. 6376). IDP Education Australia.

Mak, A. S., \& Buckingham, K. (2007). Beyond communication courses: Are there benefits in adding skills-based ExcelL sociocultural training? International Journal of Intercultural Relations, 31, 277-291.

Mamiseishvili, K. (2012). International student persistence in U.S. postsecondary institutions. Higher Education, 64, 1-17.

Misra, R., Crist, M., \& Burant, C. J. (2003). Relationships among life stress, social support, academic stressors, and reactions to stressors of international students in the United States. International Journal of Stress Management, 10, 137-157.

Navas, M., Garcia, M. C., Sanchez, J., Rojas, A. J., Pumares, P., \& Fernandez, J. S. (2005). Relative Acculturation Extended Model (RAEM): New contributions with regard to the study of acculturation. International Journal of Intercultural Relations, 29, 21-37.

Poyrazli, S., Arbona, C., Nora, A., McPherson, R., \& Pisecco, S. (2002). Relation between assertiveness, academic self-efficacy, and psychosocial adjustment among international graduate students. Journal of College Student Development, 43, 632-642.

Poyrazli, S., \& Grahame, K. M. (2007). Barriers to adjustment: Needs of international students within a semi-urban campus community. Journal of Instructional Psychology, 34, 28-45.

Poyrazli, S., \& Kavanaugh, P. R. (2006). Marital status, ethnicity, academic achievement, and adjustment strains: The case of graduate international students. College Student Journal, 40, 767-780. 
Poyrazli, S., Kavanaugh, P. R., Baker, A., \& Al-Timimi, N. (2004). Social support and demographic correlates of acculturative stress in international students. Journal of College Counseling, 7, 73-83.

Sam, D. L., \& Berry, J. W. (2010). Acculturation: When individuals and groups of different cultural backgrounds meet. Perspectives on Psychological Science, 5, 472-481.

Sarason, I. G., Sarason, B. R., Shearin, E. N., \& Pierce, G. R. (1987). A brief measure of social support: Practical and theoretical implications. Journal of Social and Personal Relationships, 4, 497-510.

Smith, R. A., \& Khawaja, N. G. (2011). A review of the acculturation experiences of international students. International Journal of Intercultural Relations, $35,699-713$

Smith, R. A., \& Khawaja, N. G. (2014). A group psychological intervention to enhance the coping and acculturation of international students. Advances in Mental Health, 12, 110-124.

Sullivan, C., \& Kashubeck-West, S. (2015). The interplay of international student acculturative stress, social support, and acculturation. Journal of International Students, 5, 1-11.

Tian, M., \& Lowe, J. (2009). Existentialist internationalization and the Chinese student experience in English universities. Compare: A Journal of Comparative and International Education, 39, 659-676.

Tolman, S. (2017). The effects of a roommate-pairing program on international student satisfaction and academic success. Journal of International Students, 7, 522-541.

Wang, K. T., Heppner, P. P., Fu, C.-C., Zhao, R., Li, F., \& Chang, C.-C. (2012). Profiles of acculturative adjustment patterns among Chinese international students. Journal of Counseling Psychology, 59, 424-436.

Ware, W. B., Ferron, J. M., \& Miller, B. M. (2013). Introductory statistics: A conceptual approach using $R$. New York: Routledge.

Wei, M., Heppner, P. P., Mallen, M. J., Ku, T.-Y., Liao, Y.-H., \& Wu, T.-F. (2007). Acculturative stress, perfectionism, years in the United States, and depression among Chinese international students. Journal of Counseling Psychology, 54, 385-394.

West, S. G., Finch, J. F., \& Curran, P. J. (1995). Structural equation models with non-normal variables: Problems and remedies. In R. Hoyle (Ed.), Structural equation modeling: Concepts, issues, and applications (pp. 5675). Thousand Oaks, CA: Sage.

Yao, C. (2016). Unfulfilled expectations: Influence of Chinese international students' roommate relationships on sense of belonging. Journal of International Students, 6, 762-778.

NELSON BRUNSTING, PhD, is the Director of Global Research and Assessment in the Center for Global Programs and Studies at Wake Forest University, North Carolina, USA. His research focuses on understanding socio-emotional outcomes of diverse populations in educational settings. Email: brunstnc@wfu.edu. 
ANDREW C. SMITH, MAT, MA, is Program Coordinator for the English Language Skills Enhancement program and part-time lecturer in the Department of Communications, Wake Forest University, North Carolina. His teaching and research interests include second language acquisition and intercultural development.

CORINNE E. ZACHRY, MA, is Research Associate at Hunter College of the City University of New York. Her research interests include promoting well-being during transitional stages, especially after the experience of adversity.

Manuscript submitted: May 6, 2017

Manuscript revised: June 26, 2017 Accepted for publication: December 20, 2017 